\title{
An interesting case of tachyarrhythmia
}

\section{Luciano Candilio, Alexander W Y Chen, Rashid Iqbal, Nandkumar Gandhi}

Department of Cardiology, East Surrey Hospital, Redhill, UK

\section{Correspondence to}

Dr Luciano Candilio, luciano. candilio@nhs.net

Accepted 8 September 2014

\section{DESCRIPTION}

A 17-year-old male patient presented to the emergency department with sudden onset of palpitations after drinking high caffeine preparations at the gym. He had no relevant medical history or family history of sudden cardiac death. He denied any use of regular medications, alcohol or illicit drugs.

On arrival, he was tachycardic (ECG in figure 1top) but haemodynamically stable. Cardiovascular examination was otherwise unremarkable; chest $\mathrm{X}$-ray and routine blood tests were normal. He was given intravenous metoprolol with no significant effect. Subsequently, his blood pressure deteriorated (ECG in figure 1-bottom) and intravenous adenosine was administered followed by further blood pressure reduction. The on-call cardiologist was contacted and synchronised direct current cardioversion with anaesthetic cover was delivered with dramatic improvement of symptoms and blood pressure (ECG in figure 2-top). The patient was subsequently referred to the local tertiary centre and underwent electrophysiological studies and successful accessory pathway ablation (figure 2-bottom).

Wolff-Parkinson-White (WPW) syndrome is the commonest pre-excitation disorder with an incidence of $0.1-0.3 \%$ in the general population and an associated sudden cardiac death risk of less than $0.6 \%{ }^{1}$ Haemodynamically stable patients can be treated pharmacologically, however atrioventricular node blockers should be avoided in atrial fibrillation/flutter with WPW as they can favour conduction through the accessory pathway, potentially

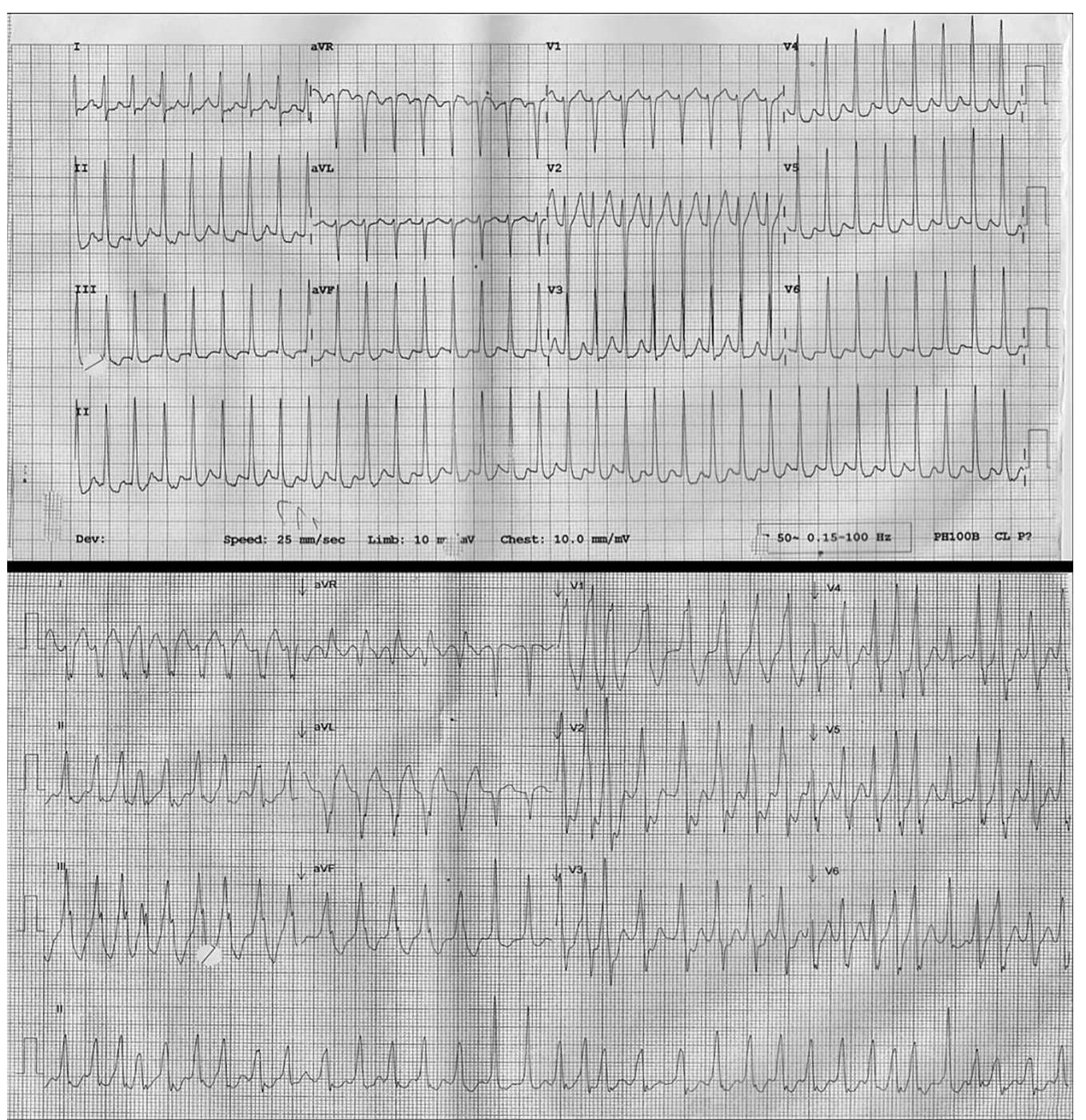

To cite: Candilio $L_{\text {, }}$ Chen AWY, lqbal $R$, et al. BMJ Case Rep Published online: [please include Day Month Year] doi:10.1136/ bcr-2014-205481

Figure 1 Top: ECG on admission showing orthodromic tachycardia where narrow regular QRS complexes are closely followed by P waves and the PR interval is longer than the RP interval: here the anterograde conduction follows the normal pathway though the atrioventricular node-His-Purkinje system and the retrograde conduction through the accessory pathway induces atrial reactivation. Bottom: ECG following administration of metoprolol and adenosine demonstrating atrial fibrillation with broad irregular complex tachycardia. 


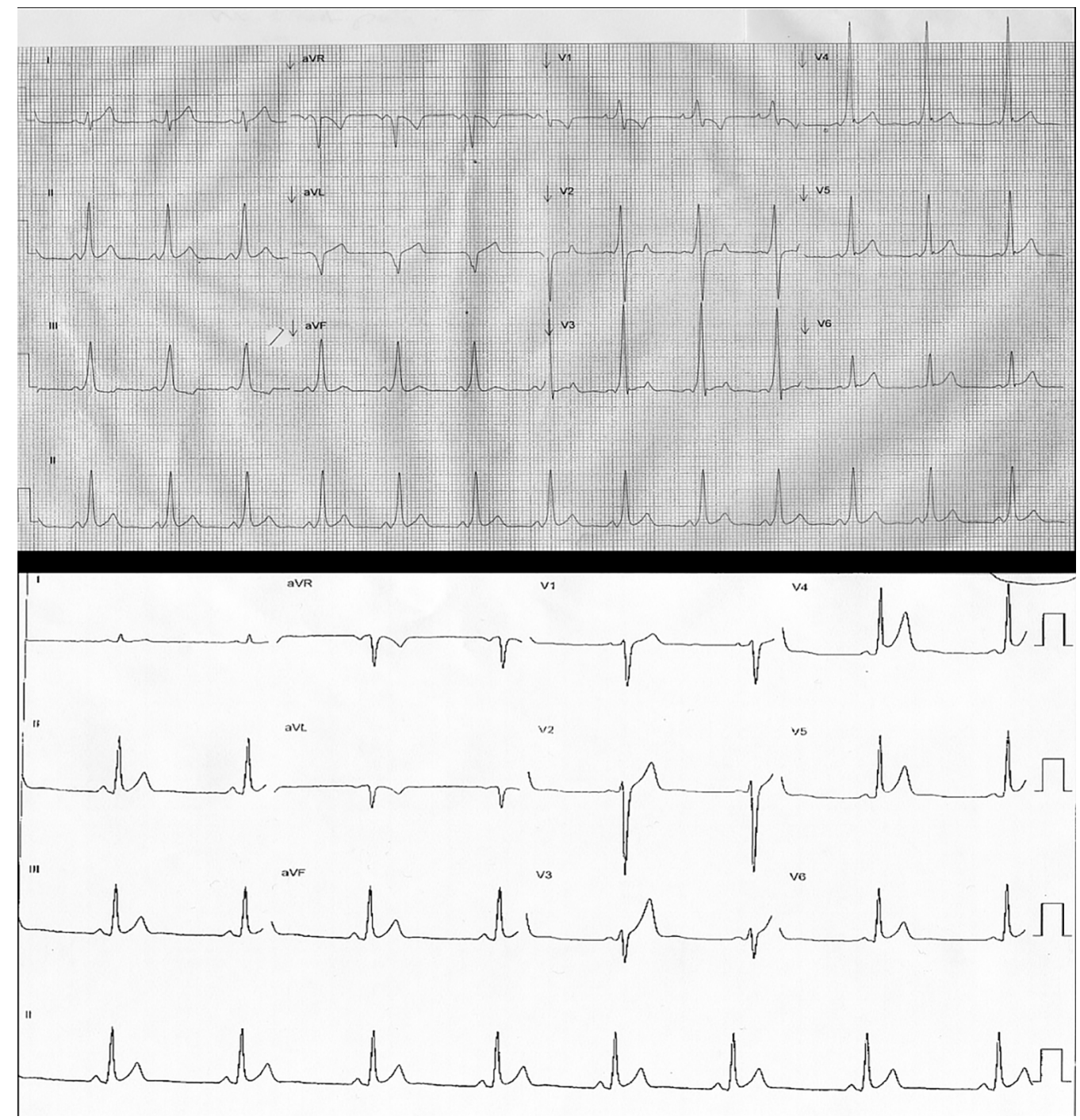

Figure 2 Top: ECG following synchronised direct current cardioversion showing sinus rhythm with typically short PR interval, $\delta$ wave and prolonged QRS duration. Here the location of the accessory pathway is left anterolateral as the $\delta$ wave has positive polarity in leads V1, III and aVF and negative polarity in aVL. Bottom: ECG following successful radiofrequency ablation demonstrating the absence of $\delta$ waves.

leading to ventricular arrhythmias. ${ }^{2}$ Radiofrequency catheter ablation is the definitive treatment of WPW syndrome with a success rate of $95 \%$ and recurrence risk of less than $5 \% .^{3}$

This case offers an exemplary spectrum of ECG presentations in WPW with disappearance of the typical $\delta$ waves following successful radiofrequency ablation.

\section{Learning points}

- Wolff-Parkinson-White (WPW) syndrome should always be suspected in a young patient presenting with symptomatic irregularly irregular broad complex tachycardia.

- Adenosine can be given in orthodromic tachycardia to induce atrioventricular (AV) node block and interrupt AV conduction, however it should be avoided in atrial fibrillation and atrial flutter with WPW or history of it as it can lead to ventricular arrhythmias by blocking the normal conduction pathway favouring 1:1 Av conduction through the accessory pathway.

- It is always advisable to seek specialist advice in complex cases of tachyarrhythmias not responding to first-line pharmacological treatment.
Acknowledgements The authors are very grateful to the patient and his parents for their availability and to colleagues and staff nurses at East Surrey Hospital and St. George's Hospital for their assistance.

Competing interests None.

Patient consent Obtained.

Provenance and peer review Not commissioned; externally peer reviewed.

\section{REFERENCES}

1 Klein GJ, Gula LJ, Krahn AD, et al. WPW pattern in the asymptomatic individual: has anything changed? Circ Arrhythmia Electrophysiol 2009;2:97-9.

2 Fengler BT, Brady WJ, Plautz CU. Atrial fibrillation in the Wolff-Parkinson-White syndrome: ECG recognition and treatment in the ED. Am J Emerg Med 2007;25:576-83.

3 Blomstrom-Lundqvist C, Scheinman MM, Aliot EM, et al. ACC/AHA/ESC guidelines for the management of patients with supraventricular arrhythmias - executive summary. A report of the American college of cardiology/American heart association task force on practice guidelines and the European society of cardiology committee for practice guidelines (writing committee to develop guidelines for the management of patients with supraventricular arrhythmias) developed in collaboration with NASPE-Heart Rhythm Society. I Am Coll Cardiol 2003:42:1493-531. 
Copyright 2014 BMJ Publishing Group. All rights reserved. For permission to reuse any of this content visit http://group.bmj.com/group/rights-licensing/permissions.

BMJ Case Report Fellows may re-use this article for personal use and teaching without any further permission.

Become a Fellow of BMJ Case Reports today and you can:

- Submit as many cases as you like

- Enjoy fast sympathetic peer review and rapid publication of accepted articles

- Access all the published articles

- Re-use any of the published material for personal use and teaching without further permission

For information on Institutional Fellowships contact consortiasales@bmjgroup.com

Visit casereports.bmj.com for more articles like this and to become a Fellow 